\title{
Nonspecific interstitial pneumonia and usual interstitial pneumonia with mutation in surfactant protein $C$ in familial pulmonary fibrosis
}

\author{
Rajni Chibbar ${ }^{1}$, Francis Shih ${ }^{1}$, Monica Baga ${ }^{2}$, Emina Torlakovic ${ }^{1}$, Kumar Ramlall ${ }^{3}$,
} Robert Skomro ${ }^{4}$, Donald W Cockcroft ${ }^{4}$ and Edmond G Lemire ${ }^{3}$

${ }^{1}$ Department of Pathology, ${ }^{2}$ Department of Plant Sciences, ${ }^{3}$ Department of Pediatrics and ${ }^{4}$ Department of Medicine, University of Saskatchewan, Saskatoon, SK, Canada

\begin{abstract}
Nonspecific interstitial pneumonia, a recently described form of idiopathic interstitial pneumonia, is characterized by uniform involvement of the alveolar septae with interstitial inflammation and variable amounts of fibrosis. Histological observations differentiate nonspecific interstitial pneumonia from usual interstitial pneumonia and clinically, patients with a nonspecific interstitial pneumonia pattern show better prognosis than those with usual interstitial pneumonia. We have genetically analyzed a family with a history of usual interstitial pneumonia. Most of the patients presented as adults and their biopsies showed a pattern consistent with usual interstitial pneumonia. However, three family members presented in early childhood and their biopsies revealed a nonspecific interstitial pneumonia pattern. The inheritance pattern of usual interstitial pneumonia is consistent with autosomal dominant inheritance with variable expression. DNA sequence analyses of the surfactant protein $C$ gene in children with nonspecific interstitial pneumonia and adults with usual interstitial pneumonia exhibit a common heterozygous mutation located in exon 5 . The mutation causes a Leu $_{188}$ to Gln $_{188}$ change in the carboxy-terminal region of prosurfactant protein $C$, possibly affecting peptide processing. These observations suggest that individuals with this particular mutation in surfactant protein $C$ gene might be at increased risk of interstitial lung disease of variety of types.
\end{abstract}

Modern Pathology (2004) 17, 973-980, advance online publication, 7 May 2004; doi:10.1038/modpathol.3800149

Keywords: surfactant protein $C$; interstitial pulmonary fibrosis; nonspecific interstitial pneumonia; usual interstitial pneumonia

The clinical manifestations of idiopathic interstitial pneumonia are often subtle and nonspecific. Classification and diagnosis of idiopathic interstitial pneumonia is complicated by overlapping histological abnormalities consisting of variable amounts of inflammation, accumulation of intra-alveolar macrophages, and fibrosis. Only recently has a multidisciplinary consensus classification of idiopathic interstitial pneumonia been published in an attempt to standardize the classification and diagnostic criteria for idiopathic interstitial pneumonia. ${ }^{1}$ The latest classification of idiopathic interstitial pneumonia contains seven entities in-

Correspondence: Dr R Chibbar, MBBS, PhD, FRCPC, Department of Pathology, Royal University Hospital, 103 Hospital Drive, Saskatoon, SK, Canada S7N 0W8.

E-mail: rajni.chibbar@saskatoonhealthregion.ca

Received 14 August 2003; revised 7 January 2004; accepted 12 January 2004; published online 7 May 2004 cluding usual interstitial pneumonia (idiopathic pulmonary fibrosis) and nonspecific interstitial pneumonia. ${ }^{1}$

Several familial cases of usual interstitial pneumonia have been known since the 1950s. ${ }^{2-8}$ Two separate families with usual interstitial pneumonia have been previously reported ${ }^{2,4}$ from our hospital. These studies included multiple affected individuals over several generations. The authors proposed a genetic basis to familial usual interstitial pneumonia and speculated that this condition was transmitted in an autosomal dominant manner with reduced penetrance.

Recently, mutations in the gene encoding surfactant protein $C$ have been identified in familial as well as in sporadic cases. ${ }^{9-11}$ Surfactant protein $C$ is a hydrophobic surfactant protein synthesized in type II pneumocytes and plays a role in maintaining surface tension. ${ }^{12}$ It is translated as a large precursor polypeptide and sequentially processed to a mature 
surfactant protein $C$ protein, which is stored in lamellar bodies and secreted into the alveolar space.

Two children, descendants from one of the original families reported previously, ${ }^{4}$ were admitted to our hospital with persistent respiratory symptoms. Herein, we have investigated a possible relationship between a mutation in the surfactant protein $C$ gene and the histopathology of lung biopsies obtained from these children. Our findings suggest a possible increased risk of interstitial lung disease in patients with a putative surfactant protein-C mutation.

\section{Materials and methods}

\section{Family Information}

Three individuals (V:3, V:4, and III:10) from Family Group 2 reported by Donohue et $a l^{4}$ came to our attention when they were admitted for respiratory problems (Figure 1). Additional symptomatic family members were identified by history. Lung tissue was available from four individuals. Clinical and pathological information on other family members was previously published elsewhere. ${ }^{4,11}$ Hematoxylin and eosin-stained slides were available for five cases and formalin-fixed/paraffin-embedded tissue blocks were available for four cases. Trichrome and fungal stains were available for all five cases. All cases were reviewed by pulmonary pathologists from other institutes. Ethics approval was obtained from the University of Saskatchewan Ethics Committee.

\section{Isolation of DNA}

Approximately $40 \quad 10-\mu \mathrm{m}$ thick sections were cut from formalin-fixed/paraffin embedded lung tissue. DNA was isolated using the QIAGEN DNA Minikit according to the manufacturer's instructions (QIAGEN Inc., Mississauga, Ontario, Canada), quantitated by UV spectrophotometry, and stored at $-20^{\circ} \mathrm{C}$ for further use.

\section{Polymerase Chain Reaction and Sequencing}

Based on the published surfactant protein $C$ gene sequence by Glasser et $a l,{ }^{13}$ primer pairs were synthesized to amplify overlapping DNA fragments of the gene as outlined in Figure 2 and Table 1. Polymerase chain reaction (PCR) reactions with each of the six primer pairs were assembled in $50 \mu \mathrm{l}$ reaction volumes containing $200 \mathrm{ng}$ of DNA, $1.25 \mathrm{mM}$ dNTPs, $1.5 \mathrm{mM} \mathrm{MgCl}_{2}$, Platinum Taq PCR buffer, $0.2 \mathrm{U}$ of Platinum Taq polymerase (GibcoBRL Burlington, Ontario, Canada), and 5 pmol each of sense and antisense primers. Using a Perkin-Elmer Cetus Thermal Cycler, the reactions were denatu-
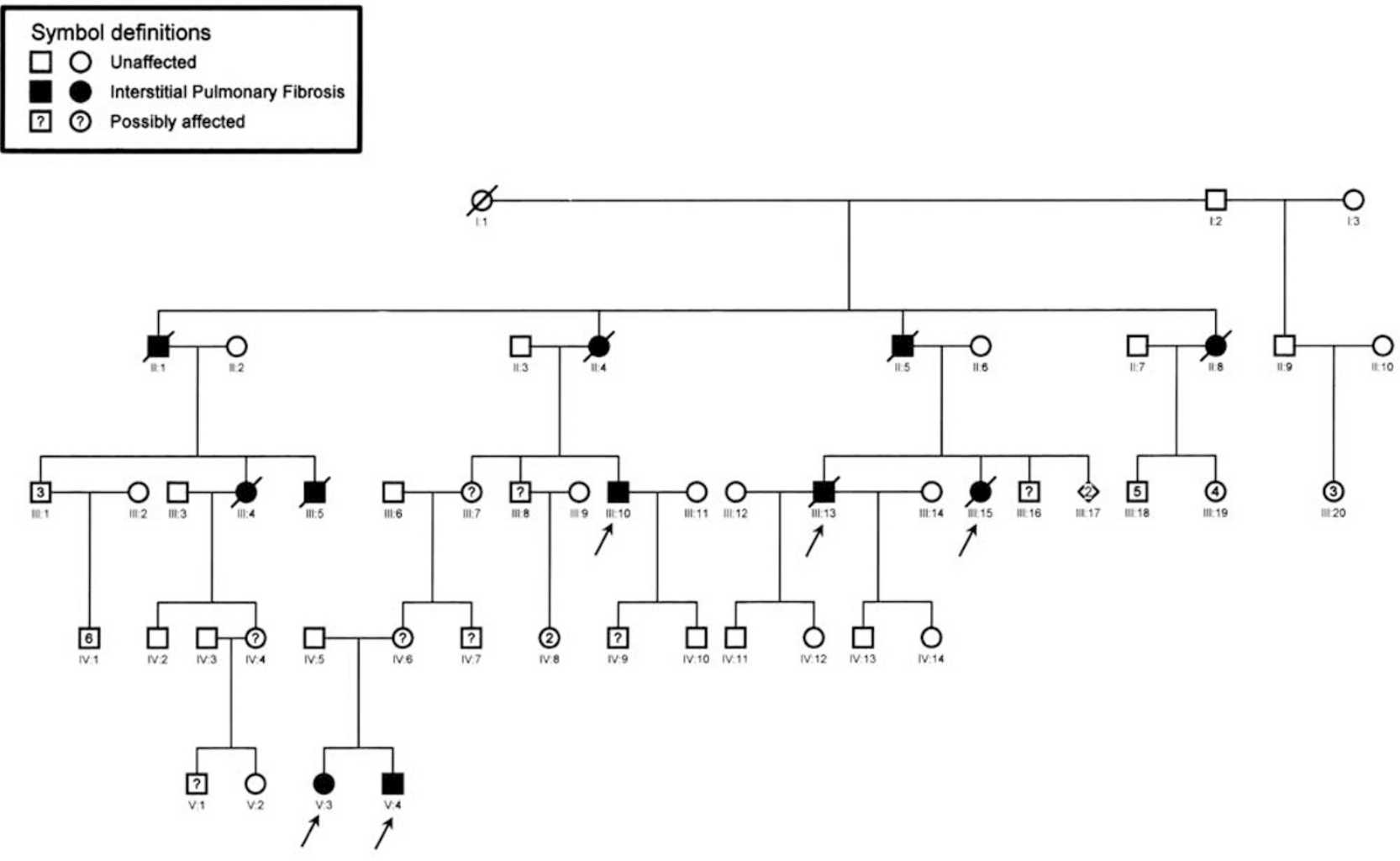

Figure 1 Pedigree of family with idiopathic interstitial pneumonia. Family members studied are indicated by arrows. 
Surfactant Protein C Gene Primers

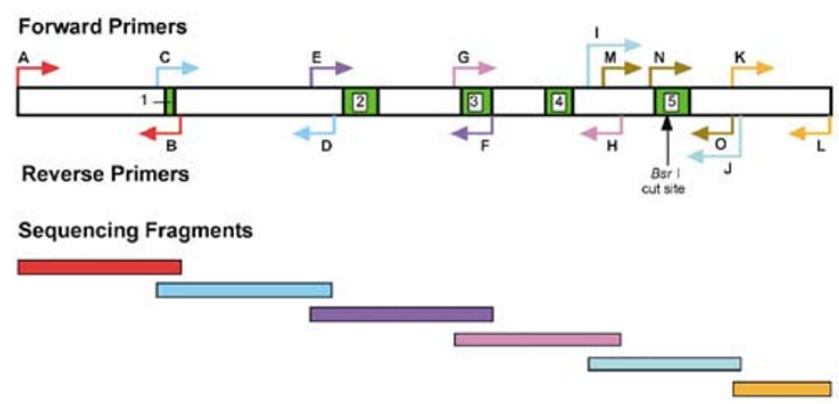

Figure 2 Schematic illustration of the $3409 \mathrm{bp}$ surfactant protein $C$ gene with exons shown in green and introns in white. Location of forward and reverse primers used for PCR amplification of gene fragments are marked with colored arrows. Two sense (M and N) and one antisense $(\mathrm{O})$ primers were used in hemi-nested reactions to generate PCR product used for the BsrI restriction enzyme digests. The DNA sequences of all primers are shown in Table 1.

Table 1 Primers sequences used for analysis of surfactant protein $C$ gene

\begin{tabular}{ll}
\hline Primer & Sequence $\left(5^{\prime} \rightarrow 3^{\prime}\right)$ \\
\hline A & GGTACCAGATATGTGGGAGGA \\
B & ACACACACGCAACCACACTC \\
C & GAGGAGAGGAGAGCATAGCAC \\
D & CAAGGAGACAGGCATGAGGT \\
E & CCTGTCCATCCATCGCATC \\
F & TGGCATACCCACCTGCTGGT \\
G & GAAGACCAGGTGGCTCCAT \\
H & CAGAAGCCACCAGGTAGTGA \\
I & GAGTGTCCGAATGGTGGCT \\
J & GGAATGTTGAGGATGGACAGAG \\
K & GCTCACAGACCGGTACTTCC \\
L & AAAGCCCGTGGATGCTC \\
$\mathrm{M}$ & GACTGCCCCTCTCCTATTCC \\
$\mathrm{N}$ & CACTTCCTACATTCCAGATGG \\
$\mathrm{O}$ & GTGGGAAGTACCGGTCTGTG \\
\hline
\end{tabular}

rated at $95^{\circ} \mathrm{C}$ for $5 \mathrm{~min}$ and subjected to 35 cycles of denaturation ( $45 \mathrm{~s}$ at $\left.94^{\circ} \mathrm{C}\right)$, annealing $\left(30 \mathrm{~s}\right.$ at $\left.65^{\circ} \mathrm{C}\right)$, and extension $\left(45 \mathrm{~s}\right.$ at $\left.72^{\circ} \mathrm{C}\right)$ followed by a final incubation for $10 \mathrm{~min}$ at $72^{\circ} \mathrm{C}$. The reaction products underwent $1.5 \%$ agarose gel electrophoresis and amplified PCR products were excised, purified using the QIAquick Gel Extraction Kit (QIAGEN), precipitated, washed twice with $80 \%$ ethanol, resuspended in $\mathrm{H}_{2} \mathrm{O}$, and quantitated. DNA sequencing of the purified fragments was performed using primers described in Figure 1 and the dye terminator cycle sequencing technique followed by analysis on an ABI PRISM 377 DNA sequencer. Obtained DNA sequences were assembled and analyzed using the Lasergene software (DNAstar Inc.).

To generate the required amount of PCR product for restriction enzyme digests, hemi-nested PCR reactions were performed. An amount of $2 \mu \mathrm{l}$ of amplicon obtained from the first round of PCR amplification with primers $\mathrm{M}$ and $\mathrm{O}$ across exon 5 was reamplified using primers $\mathrm{N}$ and $\mathrm{O}$ (Figure 2). A $20 \mu \mathrm{l}$ aliquot of reamplified product was digested with $15 \mathrm{U}$ of BsrI using reagents and conditions supplied by the manufacturer (New England Biolabs, Mississauga, Ontario, Canada). The presence or absence of the BsrI restriction site was analyzed by $2 \%$ agarose gel electrophoresis of digested and undigested samples. DNA from healthy subjects and sporadic idiopathic pulmonary fibrosis patients were used as control.

\section{Clinical Information}

Case No. 1

V:3 (Figure 1) was first admitted to our hospital at 17 months of age in March 1999 because of respiratory distress requiring oxygen and failure to thrive. There was marked clubbing of the patient's fingers and toes and she had suffered from tachypnea and intercostal indrawing since at least 1 month of age. At 14 months of age, she was hospitalized for confirmed respiratory syncytial virus pneumonia. A review of the family history revealed multiple relatives with idiopathic pulmonary fibrosis. Her clinical status did not improve. A lung biopsy performed 4 months later showed a nonspecific interstitial pneumonia-like pattern. She received very high dose (methylprednisone $15 \mathrm{mg} / \mathrm{kg} /$ day $\times$ 3 days $\mathrm{s}$ monthly) of pulse steroid treatment and hydroxychloroquine for her interstitial pneumonia. There were frequent respiratory exacerbations. Since then, she has continued to be tachypneic and has persistent bilateral crackles in the absence of acute infection. Digital clubbing persists and she fails to thrive. This clinical pattern is characteristic of interstitial lung disease.

Case No. 2

$\mathrm{V}: 4$ (Figure 1) is the younger brother of V:3. In January 2000, he was admitted to our hospital because of acute respiratory distress later found to be brought on by an influenza A infection. The chest $\mathrm{X}$-ray and CT demonstrated diffuse ground glass airspace disease with evidence of alveolitis. Interstitial pneumonia was suspected and he underwent a lung biopsy, which showed a similar nonspecific interstitial pneumonia pattern as found in his sister. Concurrent evaluations for a primary or secondary immunodeficiency, hypersensitivity pneumonia, and other causes of secondary interstitial pneumonia were negative. Similar to his sister, he required treatment with very high doses of pulse steroid and hydroxychloroquine. He has had persistent failure to thrive requiring insertion of a gastrotomy-tube, ongoing tachypnea, persistent bilateral crackles in the absence of acute infection and digital clubbing. This clinical pattern is also characteristic of interstitial lung disease. 
Case No. 3

III:15 (Figure 1) was reported as case 2 in Family Group 2 in the publication by Donohue et al. ${ }^{6}$ She presented in 1952 at an age of 6 months because of failure to thrive, feeding difficulties, and coughing. She progressively became more dyspneic and cyanotic and eventually succumbed at an age of 18 months after 1 year of continuous hospitalization.

\section{Case No. 4}

III:10 (Figure 1) is a great uncle to cases 1 and 2 and a first cousin to case 5 . He first presented to our hospital in 1999 and became symptomatic in 1994 with progressive exertional dyspnea, hypoxemia at rest, and obvious clubbing of his fingers. A chest Xray revealed preserved lung volumes, diffuse fine reticulations bilaterally, and cystic lesions. The CT scan identified numerous cystic lesions of varying sizes in both lungs. Most of the normal lung parenchyma was replaced, but there were several patches of normal appearing lung tissue. Pulmonary function tests demonstrated normal lung volumes with a severely reduced diffusion capacity $(18 \%$ of predicted) indicative of a restrictive lung pattern. $\mathrm{He}$ declined a lung biopsy. The patient underwent a double lung transplant in November 2000. Histological analysis of the explanted lung tissue showed usual interstitial pneumonia-like patterns with extensive fibrosis, numerous cystic areas (honeycomb change), intervening normal lung parenchyma, and fibroblastic foci.

\section{Case No. 5}

III:13 (Figure 1) was a sibling to case 3. Clinical information was obtained from family interviews and a previous publication. ${ }^{13}$ He first presented in 1989 with dyspnea, cough, and clubbing. The patient had an open lung biopsy, which showed usual interstitial pneumonia. The disease progressed and he required a double lung transplant, but he eventually died in 2000 .

\section{Results}

The clinical findings of the 11 known affected family members are summarized in Table 2. In adults, the average age of diagnosis was 31 years (range 17-57 years) and the most common presenting complaints were cough and dyspnea. The three children presented at an average age of 9 months (range 4-17 months). Two of the children presented with viral pneumonia before being diagnosed and all three children presented with failure to thrive and dyspnea. Clubbing of the fingers was reported in six of the adults and two of the three children. The adults survived an average of 18 years (range 5-46 years) after the diagnosis was initially made. Two of the children are still symptomatic, whereas one child died 12 months after the initial diagnosis. The clinical variability seen here in this family is characteristic of an autosomal dominant disorder with variable expression. There was no obvious sex predilection with the six males and five female members affected.

The histopathological findings from the open lung biopsies obtained from the three children (Figure 3a-c) were identical and showed features of nonspecific interstitial pneumonia characterized by homogeneous interstitial pneumonia with variable number of alveolar macrophages and type II pneumocyte hyperplasia. The alveolar septae were widened by a combination of inflammatory cells and plump to oval spindle-shaped cells. The inflammatory infiltrate was predominantly composed of lymphocytes, scattered plasma cells, and rare neutrophils and eosinophils. Trichrome stain revealed the presence of collagen within the septae. No fibroblastic foci, accumulation of granular amorphous eosinophilic material resembling exudate as seen in pulmonary alveolar proteinosis, and fungal organisms were identified.

The two adult patients studied had both received lung transplants. In one case, no biopsy of the lung tissue was performed prior to the transplant, whereas the second patient had a biopsy, approximately 3 years before transplant. Sections from the

Table 2 Summary of patient information

\begin{tabular}{|c|c|c|c|c|c|}
\hline Patient & Sex & Age at diagnosis & Clinical manifestations & Current status & Pathology \\
\hline II:1 & $\mathrm{M}$ & 29 years & Cough, dyspnea, clubbing weight loss & Deceased at 40 years & NSIP \\
\hline II:4 & $\mathrm{F}$ & 57 years & Cough, dyspnea & Deceased at 68 years & UIP \\
\hline II:5 & $\mathrm{M}$ & 20 years & Cough, dyspnea, clubbing & Deceased at 66 years & UIP \\
\hline II:8 & $\mathrm{F}$ & 41 years & Dyspnea, clubbing & Deceased at 58 years & UIP \\
\hline III:4 & $\mathrm{F}$ & 17 years & Cough, dyspnea, clubbing & Deceased at 22 years & UIP \\
\hline III:5 & $\mathrm{M}$ & 18 years & Cough, dyspnea & Deceased at 43 years & UIP \\
\hline III:10 & $\mathrm{M}$ & 32 years & Dyspnea, clubbing & Alive at 48 years & UIP \\
\hline III:13 & M & 34 years & Dyspnea, clubbing & Deceased at 52 years & UIP \\
\hline III:15 & $\mathrm{F}$ & 6 months & Failure to thrive, dyspnea, cyanosis & Deceased at 18 months & NSIP \\
\hline $\mathrm{V}: 3$ & $\mathrm{~F}$ & 17 months & Failure to thrive, dyspnea, clubbing & Alive at 5 years & NSIP \\
\hline $\mathrm{V}: 4$ & $\mathrm{M}$ & 4 months & Failure to thrive, dyspnea, clubbing & Alive at 3 years & NSIP \\
\hline
\end{tabular}

NSIP, nonspecific interstitial pneumonia; UIP, usual interstitial pneumonia.

Source: Donohue et al ${ }^{4}$ and Thomas et al. ${ }^{11}$ 


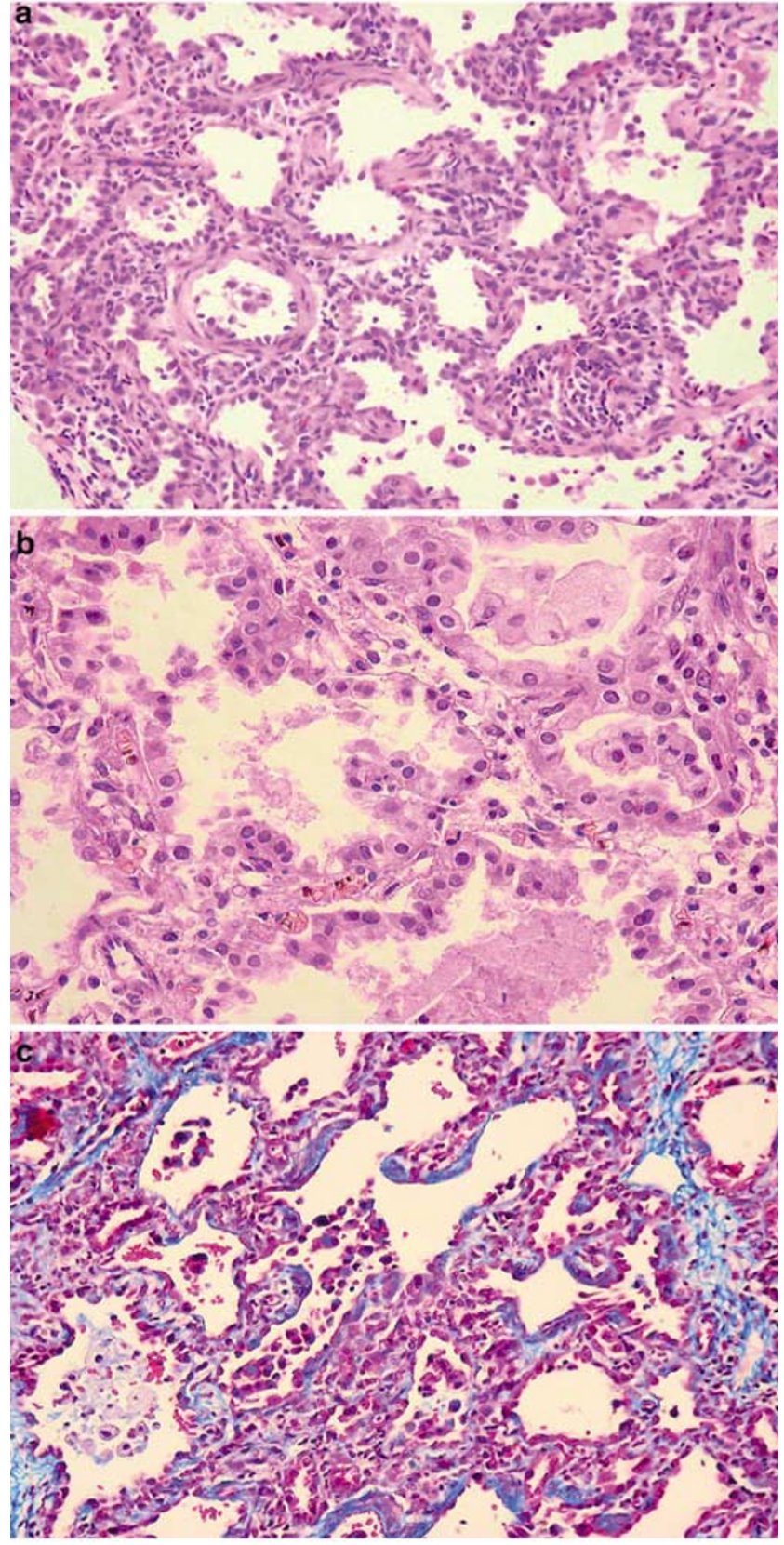

Figure 3 (a, b) Nonspecific interstitial pneumonia pattern in lung biopsies from V:4 showing homogeneous expansion of interstitium by inflammatory cells, myofibroblasts, and Type II pneumocytes hyperplasia. (c) Trichrome stain showing collagen within interstitium.

three available specimens showed an usual interstitial pneumonia-like pattern with extensive fibrosis (Figure 4a-c). The degree of fibrosis was relatively less in the biopsy specimen prior to transplantation. Most of the explanted lung sections showed end-stage pulmonary fibrosis with honeycomb changes. These regions showed extensive fibrosis, marked smooth muscle hyperplasia, chronic inflammation, dilated air spaces, airways with focal mucin plugging, and carbon pigment
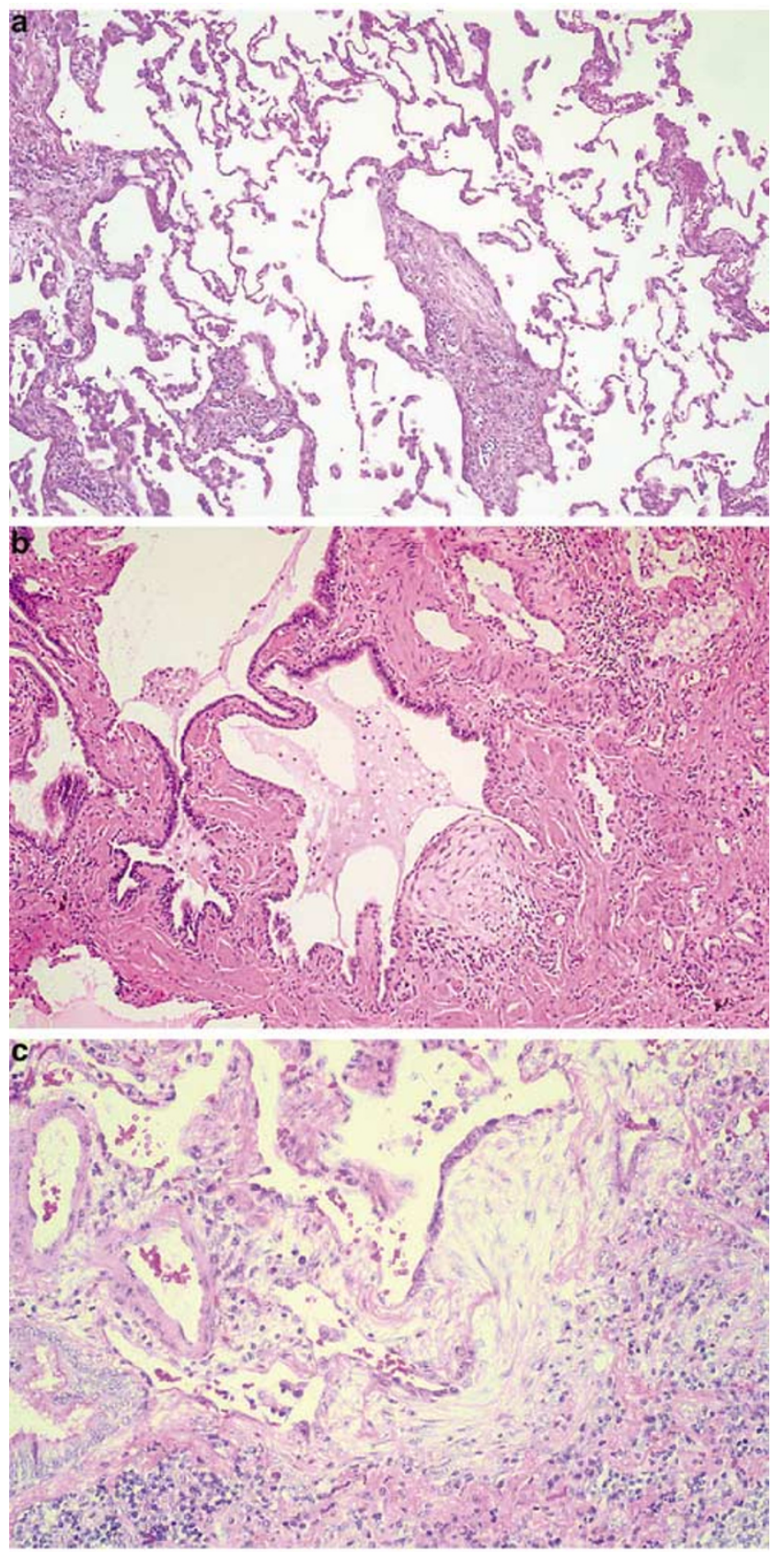

Figure 4 Usual interstitial pneumonia pattern showing (a) patchy fibrosis with intervening normal lung parenchyma, (b, c) marked fibrosis with collagenous scarring, honeycomb changes and, fibroblastic foci.

deposition. There were scattered fibroblastic foci characterized by small interstitial aggregates of spindle-shaped fibroblasts and myofibroblasts within myxoid stroma. Some of the alveoli showed type II pneumocyte hyperplasia and focal distention of alveolar spaces by alveolar macrophages. Focal intervening regions of relatively normal lung parenchyma were present. The pathology findings were similar to those of previously published adult cases who were diagnosed with usual interstitial pneumonia. 
To study if the nonspecific interstitial pneumonia and usual interstitial pneumonia pattern diagnosed in the family cases was associated with mutation(s) within the surfactant protein $C$ gene, genomic DNA was isolated from paraffin blocks of cases followed by DNA sequencing of the surfactant protein $C$ gene. Alignment of the surfactant protein $C$ sequences obtained from cases V:3, V:4, III:10, and III:13 and sporadic idiopathic pulmonary fibrosis control revealed one nucleotide difference. All cases showed a T/A double peak in the DNA trace at one position within exon 5, whereas the control sequences showed only a $\mathrm{T}$ peak corresponding to the published sequence (Figure 5).$^{13}$ The analysis of the cases suggested heterozygosity at this position of the surfactant protein $C$ gene, which was confirmed by sequencing the opposite strand. The $\mathrm{T}$ to $\mathrm{A}$ change on one allele of the cases resulted in a glutamine instead of a highly conserved leucine residue at amino acid 188 of the encoded surfactant protein $C$ proprotein. This mutation was identical to the mutation previously identified in other individuals from this kindred. ${ }^{11}$ Further DNA sequence analysis of exon 5 from the seven patients with sporadic interstitial pulmonary fibrosis, four members of familial idiopathic pulmonary fibrosis from another kindred, and two healthy individuals did not reveal any heterozygosity at codon encoding $\mathrm{Leu}_{188}$. The mutation at codon 188 in the studied family corresponded to a recognition site for endonuclease $B s r I$ within the coding sequence. To confirm the presence of a $B s r I$ restriction site on one allele of exon 5 in patients carrying the surfactant protein $C$ gene mutation, PCR amplified fragments of this region were restricted with BsrI. This analysis showed a partial restriction of the exon 5 PCR fragment from all cases but no digest was obtained from fragments amplified from sporadic idiopathic pulmonary fibrosis used as a control. Thus, the analysis confirmed the presence of a heterozygous mutation at codon 188 as suggested by the DNA sequence analysis (Figure 6).

\section{Discussion and conclusion}

In this report, we have demonstrated a recurrent mutation in exon 5 of the surfactant protein $C$ gene in four affected family members from one kindred with apparent autosomal dominant usual interstitial pneumonia. Some individuals from this family presented in childhood with respiratory symptoms, whereas others became clinically symptomatic only as adults. The histological findings in the specimens obtained from individuals within these two groups were quite different. All individuals with childhood onset showed histopathological features of nonspecific interstitial pneumonia, whereas tissue specimens from the adults were diagnosed as usual interstitial pneumonia. Similarly, Mak et $a l^{6}$ has described a family where an infant had nonspecific
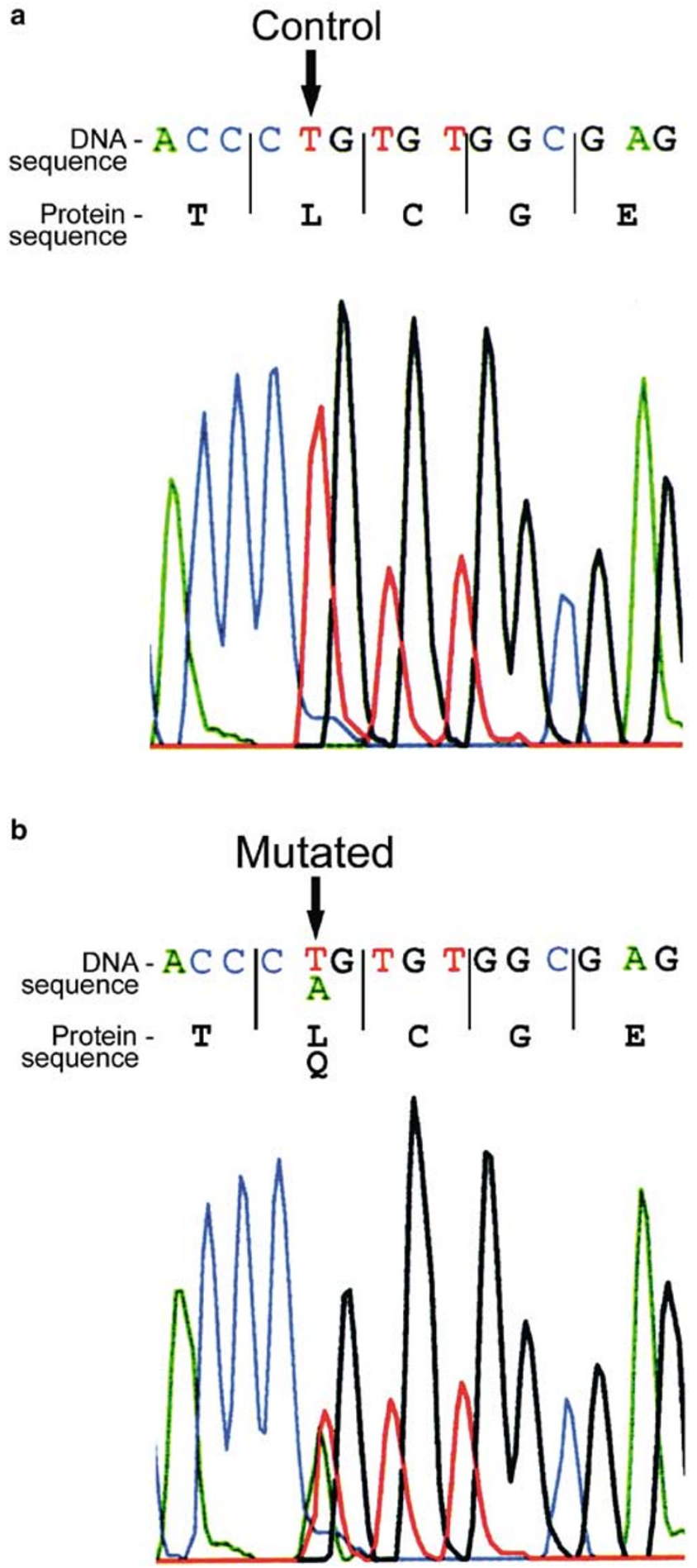

Figure 5 Identification of surfactant protein $C$ gene mutation. DNA sequence analysis of surfactant protein $C$ exon 5 from (a) control and (b) cases V:3, V:4, III:10, and III:13. A T to A transversion on one allele causes a $\operatorname{Leu}_{188}$ to $\mathrm{Gln}_{188}$ change in the encoded surfactant protein $C$ proprotein.

interstitial pneumonia-like features and an uncle presented with idiopathic pulmonary fibrosis at the age of 42 years. In the case reported by Nogee et $a l,{ }^{9}$ the lung biopsy of an infant daughter of a woman diagnosed with desquamative interstitial pneumo- 


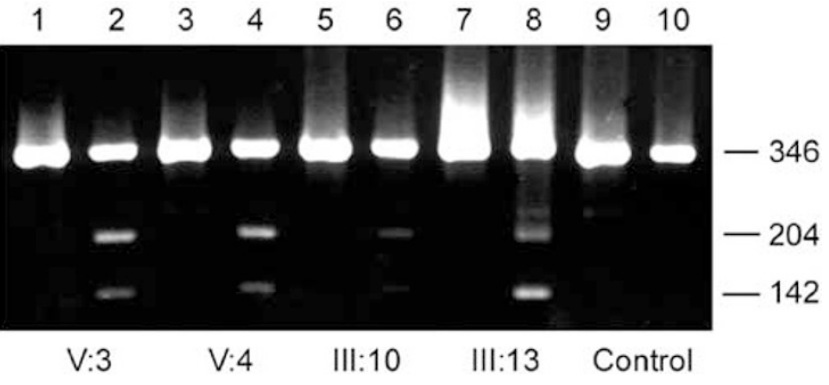

Figure 6 Restriction analysis of amplified exon 5 sequences of the surfactant protein $C$ gene from affected family members and control. Cases analyzed corresponds to pedigree symbols in Figure 1 and control sample was from a patient with sporadic interstitial pulmonary fibrosis. Undigested samples were analyzed in lanes $1,3,5,7$, and 9 and digested samples were run on lanes 2, 4, 6, 8, and 10 . The presence of a BsrI site caused by $\mathrm{T}$ to A transversion at codon 188 generated two bands (204, $142 \mathrm{bp}$ ), whereas the normal allele lacking the BsrI restriction site remained undigested (346 bp).

nia at the age of 1 year showed features of cellular nonspecific interstitial pneumonia. The mother died shortly after the birth of her daughter at age 15 years and the autopsied lung showed a usual interstitial pneumonia-like pattern. Interestingly, further studies demonstrated a heterozygous mutation within the gene encoding surfactant protein $C$ in both mother and infant, which abolished a donor splice site resulting in alternate messenger RNA splicing. ${ }^{9}$ This mutation appears to alter the carboxy-terminal (C-terminal) region of the pro-surfactant protein $C$, which remains unprocessed and accumulates in the type II pneumocytes.

Our study shows that both children and adults with nonspecific interstitial pneumonia and usual interstitial pneumonia patterns, respectively, carry a common mutation within the surfactant protein $C$ gene similar to the mutation reported by Thomas et al. ${ }^{11}$ The heterozygous mutation in our kindred alters the C-terminus of the unprocessed polypeptide. This region of pro-surfactant protein $C$ appears to be important in processing and maturation of prosurfactant protein $C$ in pneumocytes. ${ }^{11,14-17}$ Furthermore, Keller et a ${ }^{18}$ has demonstrated that absence of the 22 C-terminal amino acids interfered with the processing of pro-surfactant protein $C$ and resulted in cytoplasmic accumulation of protein. Recently, many autosomal dominant diseases caused by alterations in protein folding and transport result in defective targeting of both the mutant protein and coexpressed native forms have been characterized. ${ }^{19-21}$ Analogous to hepatocyte injury in $\alpha-1$ antitrypsin deficiency, ${ }^{22-24}$ defective processing and accumulation of unprocessed pro-surfactant protein $C$ in type II pneumocytes may cause cell injury and death followed by formation of reactive fibroblastic foci, a hallmark of usual interstitial pneumonia. ${ }^{25}$ Abnormal accumulation of pro-surfactant protein $C$ in type II pneumocytes may be a stimulus producing repeated episodes of epithelial injury in the absence of ongoing inflammation and sufficient to stimulate the development of fibrosis. The key histologic appearance of usual interstitial pneumonia includes a temporal heterogeneous pattern comprising of patchy scarring of lung parenchyma with intervening normal alveoli. The lesions appear to be of different ages with a mixture of active inflammation and fibroblastic foci believed to reflect ongoing injury and established fibrosis thought to reflect older injury and repair. The active sites of fibrosis (fibroblastic foci) are typically present at the edge of the dense scars. ${ }^{26,27}$

Nonspecific interstitial pneumonia and usual interstitial pneumonia are thought to be distinct histological findings and not known to be related. Nonspecific interstitial pneumonia is currently the most important lesion in the differential diagnosis of usual interstitial pneumonia. ${ }^{1,28}$ Nonspecific interstitial pneumonia differs from usual interstitial pneumonia in having a distinct pattern of interstitial pneumonia characterized by chronic interstitial inflammation and fibrosis that appear temporally uniform suggesting that inflammation and fibrosis are of a similar age. ${ }^{28-30}$ Interestingly, Flaherty et $a l^{30}$ found both usual interstitial pneumonia and nonspecific interstitial pneumonia-like features in $26 \%$ of cases with multiple lobe lung biopsies in the same patient suggesting coexistence of nonspecific interstitial pneumonia and usual interstitial pneumonia like pattern in some patients. Katzenstein et $a l^{31}$ recently showed that both patterns of interstitial lung diseases may be seen in some patients and suggested that these two patterns may be due to different severity of same injury or due to different injuries.

Slowly resolving acute lung injury has been associated with nonspecific interstitial pneumonia. ${ }^{28,32}$ It is known that injury to type II pneumocytes is associated with increased production of lamellar bodies and surfactant. ${ }^{12}$ This may lead to increased accumulation of unprocessed pro-surfactant protein $C$ in type II epithelial cells in patients with mutation in surfactant protein $C$, and therefore resulting in diffuse cell injury producing a nonspecific interstitial pneumonia-like pattern as noted in our patients. The lung biopsy for two children at our hospital was performed at least 4 months after viral infection and both the children, 4 years after the lung biopsy, continue to have signs and symptoms of interstitial lung disease. The only other report that described nonspecific interstitial pneumonia in the child and usual interstitial pneumonia in related adult was by Mak et al. ${ }^{6}$ Since our patients had viral disease and the infant described by Mak et $a l^{6}$ had Pneumocystis carinii pneumonia, it appears that respiratory infection may be a possible trigger for early presentation of interstitial lung disease.

The full implications of a surfactant protein $C$ gene mutation and its relation to the development of idiopathic interstitial pneumonia remain to be 
determined. It is not clear whether the associated interstitial lung injury is secondary to deficiency of functional surfactant $\mathrm{C}$, accumulation of pro-surfactant protein $C$ that per se could be pneumotoxic, or other mechanisms. Whatever the mechanism of lung injury may be, our and previous reports indicate that surfactant protein $C$ mutations in carboxy terminus are associated with both, nonspecific interstitial pneumonia and usual interstitial pneumonia.

\section{Acknowledgement}

We thank the Royal University Hospital Foundation for the funding provided for this research.

\section{References}

1 American Thoracic Society, European Respiratory Society International. American Thoracic Society/ European Respiratory Society International: multidisciplinary consensus classification of the idiopathic interstitial pneumonias. Am J Respir Crit Care Med 2002;165:277-304.

2 Adelman AG, Chertkow G, Hayton RC. Familial fibrocystic pulmonary dysplasia: a detailed family study. Can Med Assoc J 1966;95:603-610.

3 Bitterman PB, Rennard SI, Keogh BA, et al. Familial idiopathic pulmonary fibrosis: evidence of lung inflammation in unaffected family members. N Engl J Med 1986;314:1343-1347.

4 Donohue WL, Laski B, Uchida I, et al. Familial fibrocystic pulmonary dysplasia and its relation to the hamman-rich syndrome. Pediatrics 1959;24: 786-813.

5 Hewitt CJ, Hull D, Keeling JW. Fibrosing alveolitis in infancy and childhood. Arch Dis Child 1977;52:22-37.

6 Mak H, Moser RL, Hallett JS, et al. Usual interstitial pneumonitis in infancy: clinical and pathologic evolution. Chest 1982;82:124-126.

7 Marshall RP, Puddicombe A, Cookson WO, et al. Adult familial cryptogenic fibrosing alveolitis in the United Kingdom. Thorax 2000;55:143-146.

8 Riedler J, Golser A, Huttegger I. Fibrosing alveolitis in an infant. Eur Respir J 1992;5:359-361.

9 Nogee LM, Dunbar III AE, Wert SE, et al. A mutation in the surfactant protein $C$ gene associated with familial interstitial lung disease. $N$ Engl J Med 2001;344: $573-579$.

10 Nogee LM, Dunbar III AE, Wert SE, et al. Mutations in the surfactant protein $C$ gene associated with interstitial lung disease. Chest 2002;121:20S-21S.

11 Thomas AQ, Lane K, Phillips III J, et al. Heterozygosity for a surfactant protein $C$ gene mutation associated with UIP and cellular NSIP in one kindred. Am J Respir Crit Care Med 2002;165:1322-1328.

12 Beers MF, Fisher AB. surfactant protein $C$ : a review of its unique properties and metabolism. Am J Physiol 1992;263:L151-L160.

13 Glasser SW, Korfhagen TR, Perme CM, et al. Two SP-C genes encoding human pulmonary surfactant proteolipid. J Biol Chem 1988;263:10326-10331.

14 Beers MF, Kim CY, Dodia C, et al. Localization, synthesis, and processing of surfactant protein $C$ in rat lung analyzed by epitope-specific antipeptide antibodies. J Biol Chem 1994;269:20318-20328.

15 Beers MF, Lomax CA, Russo SJ. Synthetic processing of surfactant protein $C$ by alveolar epithelial cells: the $\mathrm{COOH}$ terminus of proSP-C is required for posttranslational targeting and proteolysis. J Biol Chem 1998;273:15287-15293.

16 Conkright JJ, Bridges JP, Na CL, et al. Secretion of surfactant protein $C$, an integral membrane protein, requires the N-terminal propeptide. J Biol Chem 2001; 276:14658-14664.

17 Wang WJ, Mulugeta S, Russo SJ, et al. Deletion of exon 4 from human surfactant protein $C$ results in aggresome formation and generation of a dominant negative. J Cell Sci 2003;116:683-692.

18 Keller A, Stenhilber W, Schafer K, et al. The C-terminal domain of the pulmonary surfactant protein $C$ precursor contains signals for intracellular targeting. Am J Respir Cell Mol Biol 1992;6:601-608.

19 Carrell RW, Lomas DA. Alpha 1-antitrypsin deficiencya model for conformational diseases. N Engl J Med 2002;346:45-53.

20 Gow A, Lazzarini RA. A cellular mechanism governing the severity of Pelizaeus-Merzbacher Disease. Nat Genet 1996;13:422-428.

21 Notterpek L, Ryan MC, Tobler AR, et al. PMP22 accumulation in aggresomes: implications for CMT1A pathology. Neurobiol Dis 1999;6:450-460.

22 Perlmutter DH. Liver injury in $\alpha 1$-antitrypsin deficiency: an aggregated protein induces mitochondrial injury. J Clin Invest 2002;110:1579-1583.

23 Teckman JH, Qu D, Perlmutter DH. Molecular pathogenesis of liver disease in $\alpha 1$-antitrypsin deficiency. Hepatology 1996;24:1504-1516.

24 Sveger T. The natural history of liver disease in $\alpha 1$ antitrypsin deficient children. Acta Paediatr Scand 1988;77:847-851.

25 Katzenstein AL, Myers JL. Idiopathic pulmonary fibrosis: clinical relevance of pathologic classification. Am J Respir Crit Care Med 1998;157:1301-1315.

26 Katzenstein AL, Askin FB. Katzenstein and Askin's Surgical Pathology of Non-neoplastic Lung Disease 3rd edn. WB Saunders: Philadelphia, PA, 1997.

27 Nagai S, Kitaichi M, Izumi T. Classification and recent advances in idiopathic interstitial pneumonia. Curr Opin Pulmon Med 1998;4:256-260.

28 Katzenstein AL, Fiorelli RF. Nonspecific interstitial pneumonia/fibrosis: histologic features and clinical significance. Am J Surg Pathol 1994;18:136-147.

29 Daniil Z, Gilchrist FC, Nicholson AG, et al. A histologic pattern of nonspecific interstitial pneumonia is associated with a better prognosis than usual interstitial pneumonia in patients with cryptogenic fibrosing alveolitis. Am J Respir Crit Care Med 1999; 160:899-905.

30 Flaherty KR, Travis WD, Colby TV, et al. Histopathologic variability in usual and nonspecific interstitial pneumonias. Am J Respir Crit Care Med 2001;164: 1722-1727.

31 Katzenstein AL, Zisman DA, Litzky LA, et al. Usual interstitial pneumonia: histologic study of biopsy and explant specimens. Am J Surg Pathol 2002;26: 1567-1577.

32 Cottin V, Donsbeck AV, Revel D, et al. Nonspecific interstitial pneumonia: individualization of a clinicopathologic entity in a series of 12 patients. Am J Respir Crit Care Med 1998;158:1286-1293. 